\title{
MHY-449, a novel dihydrobenzofuro[4,5-b][1,8] naphthyridin-6-one derivative, mediates oxidative stress-induced apoptosis in AGS human gastric cancer cells
}

\author{
SEON HEE KIM* ${ }^{*}$ YONG JUNG KANG* , BOKYUNG SUNG, DONG HWAN KIM, \\ HYUN SOOK LIM, HYE RIM KIM, SEONG JIN KIM, JEONG-HYUN YOON, \\ HYUNG RYONG MOON, HAE YOUNG CHUNG and NAM DEUK KIM
}

College of Pharmacy, Molecular Inflammation Research Center for Aging Intervention (MRCA), Pusan National University, Busan 609-735, Republic of Korea

Received February 19, 2015; Accepted April 2, 2015

DOI: 10.3892/or.2015.3984

\begin{abstract}
MHY-449 is a novel dihydrobenzofuro[4,5-b][1,8] naphthyridin-6-one derivative designed and synthesized as a potential anticancer agent. The present study aimed to examine the anticancer activity and underlying mechanism of MHY-449. The cell viability assay performed in AGS human gastric carcinoma cells demonstrated that MHY-449 inhibited cell proliferation in a concentration-dependent manner. MHY-449 induced AGS cell death via apoptosis. The underlying molecular mechanism of MHY-449-mediated apoptosis was also investigated. MHY-449 promoted the upregulation of Fas and Fas-ligand, and activation of caspase-8, suggesting the involvement of a Fas-mediated extrinsic pathway in MHY-449-induced apoptosis. In addition, it was found that MHY-449-induced apoptosis was accompanied by the upregulation of Bax, p21 WAFI/CIPI, $\mathrm{p} 27^{\text {KIPI }}$, and p53 and suppression of Bcl-2. MHY-449 exposure activated the caspase cascade and subsequent poly(ADP-ribose) polymerase (PARP) cleavage. Furthermore, the pan-caspase inhibitor, Z-VAD-FMK, significantly attenuated MHY-449-induced apoptosis, indicating that the apoptosis was caspase-dependent. Moreover, the apoptogenic effect of MHY-449 was reactive oxygen species (ROS)-dependent. This result was confirmed by the induction of ROS by MHY-449 and by evidence that the scavenging of ROS by N-acetyl-L-cysteine inhibited MHY-449-induced cell death. Taken together, these results demonstrated that MHY-449 triggers apoptosis via caspase activation and ROS
\end{abstract}

Correspondence to: Dr Nam Deuk Kim, Department of Pharmacy, College of Pharmacy, Pusan National University, Busandaehag-ro, 63beon-gil 2, Geumjung-Gu, Busan 609-735, Republic of Korea E-mail: nadkim@pusan.ac.kr

*Contributed equally

Key words: MHY-449, gastric cancer cells, oxidative stress, apoptosis production. This result provides a novel mechanistic explanation and a basis for developing this compound as a novel candidate for human cancer therapy.

\section{Introduction}

Gastric cancer (GC) is a malignant tumor arising from the lining of the stomach. There has been a significant decrease in the incidence and mortality of this cancer type over several decades. However, GC remains the fourth most common cancer and the second most common cause of cancer death worldwide (1). The American Cancer Society estimates that $\sim 22,220$ cases of GC are to be diagnosed (13,730 males and 8,490 females), and $\sim 10,990$ individuals may succumb to GC (6,720 males and 4,270 females) in the US in 2014. Surgery at early stage is the most common treatment modality. However, most GC patients present with an advanced stage of the disease, except in countries with national screening programs such as Japan and Korea (2), where early-stage tumors are usually asymptomatic (2).

MHY-449, also known as $( \pm)-\left(R^{*}\right)-5$-methoxy-11-methyl-2(( $\left.\mathrm{R}^{*}\right)$-2-methyloxiran-2-yl)-1,2-dihydrobenzofuro[4,5-b][1,8] naphthyridin- $6(11 \mathrm{H})$-one, was designed and synthesized based on the chemical structure of psorospermin with a xanthone template and acronycine derivatives, with an acridone template (3). The cytotoxicity of MHY-449 was assessed against five human cancer cell lines including prostate cancer cell lines (LNCaP, DU145, and PC3) and breast cancer cell lines (MCF-7/ADR and MCF-7) (3,4). MHY-449 has cytotoxicity against human prostate and breast cancer cells. It suppressed cell growth by inducing G2/M phase cell cycle arrest in MCF-7/ADR cells and proliferation of androgen-independent, p53-null, and phosphatase and tensin homolog (PTEN)-negative PC3 cells by inducing apoptosis $(3,4)$. In addition, MHY-449 effectively induced G2/M phase cell cycle arrest and apoptosis in HCT116 human colon cancer cells, thereby suppressing their growth (5). This study was designed to evaluate the cytotoxic effects and underlying molecular mechanisms of action of MHY-449 against GC cells, which have yet to be adequately evalutated. 


\section{Materials and methods}

Chemicals. The simplified code name and structure of MHY-449 used in this study is shown in Fig. 1. The method for the design and synthesis of this compound was previously described (3). MHY-449 was dissolved in dimethyl sulfoxide (DMSO), stored at $-20^{\circ} \mathrm{C}$ prior to the experiments, and working dilutions were prepared in culture medium. The maximum concentration of DMSO did not exceed $0.1 \%(\mathrm{v} / \mathrm{v})$ in the treatment range, where there was no influence on cell growth. DMSO and 3-(4,5-dimethylthiazol-2-yl)-2,5-diphenyl tetrazolium bromide (MTT) were obtained from Amresco LLC (Solon, OH, USA). Propidium iodide (PI), N-acetyl-L-cysteine (NAC), and the monoclonal antibody against $\beta$-actin were purchased from Sigma-Aldrich Co. LLC (St. Louis, MO, USA). Antibodies specific for Fas, Fas-ligand (FasL), caspase-3, 8, and 9, poly(ADP-ribose) polymerase (PARP), B-cell lymphoma 2 (Bcl-2), Bcl-2-associated X protein (BAX), p53, p21 $1^{\text {WAFl/CIPI, }}$ and $\mathrm{p} 27^{K I P I}$, as well as Z-VAD-FMK, were obtained from Santa Cruz Biotechnology, Inc. (Dallas, TX, USA).

Cell culture and cell viability assay. The AGS human GC cell line was cultured in RPMI-1640 (GE Healthcare Life Sciences, Logan, UT, USA) supplemented with $10 \%$ fetal bovine serum (FBS; GE Healthcare Life Sciences), $100 \mathrm{U} /$ $\mathrm{ml}$ penicillin, and $100 \mu \mathrm{g} / \mathrm{ml}$ streptomycin (GE Healthcare Life Sciences) at $37^{\circ} \mathrm{C}$ in humidified $5 \% \mathrm{CO}_{2}$. Cell viability was determined using an MTT assay for which AGS cells were seeded in a 24-well culture plate, cultured for $24 \mathrm{~h}$ in the growth medium, and then treated with or without various reagents at the indicated concentrations. The cells were incubated in the dark with $0.5 \mathrm{mg} / \mathrm{ml} \mathrm{MTT}$ at $37^{\circ} \mathrm{C}$ for $2 \mathrm{~h}$. The formazan granules generated by the live cells were dissolved in DMSO, and the absorbance at $540 \mathrm{~nm}$ was monitored using a multi-well reader (Thermo Fisher Scientific, Vantaa, Finland).

Nuclear staining with Hoechst 33342. The cells were stained with $4 \mu \mathrm{g} / \mathrm{ml}$ Hoechst 33342 (Life Technologies Corporation, Grand Island, NY, USA) at $37^{\circ} \mathrm{C}$ for $10 \mathrm{~min}$. The cells were then observed under a fluorescence microscope.

Annexin V staining. The cells were cultured under appropriate conditions for $24 \mathrm{~h}$, subsequently harvested, trypsinized, washed once with cold phosphate-buffered saline (PBS), and suspended in $1 \mathrm{X}$ binding buffer (BD Biosciences, San Jose, CA, USA). The cells were stained with PI and Annexin V-fluorescein isothiocyanate (FITC) solution (BD Pharmingen FITC Annexin V Apoptosis Detection kit I) at room temperature for $15 \mathrm{~min}$ in the dark. The stained cells were analyzed by flow cytometry within $1 \mathrm{~h}$.

DNA fragmentation assay. The cells were lysed in a buffer containing $5 \mathrm{mM}$ Tris- $\mathrm{HCl}(\mathrm{pH} 7.5), 5 \mathrm{mM}$ ethylenediaminetetraacetic acid (EDTA), and $0.5 \%$ Triton X-100 for $30 \mathrm{~min}$ on ice. The lysates were vortexed and cleared by centrifugation at 27,000 x g for $20 \mathrm{~min}$. Fragmented DNA in the supernatant was treated with RNase, followed by proteinase $\mathrm{K}$ digestion, extraction with a phenol/chloroform/isoamyl alcohol mixture $(25: 24: 1, \mathrm{v} / \mathrm{v} / \mathrm{v})$, and isopropanol precipitation. DNA was

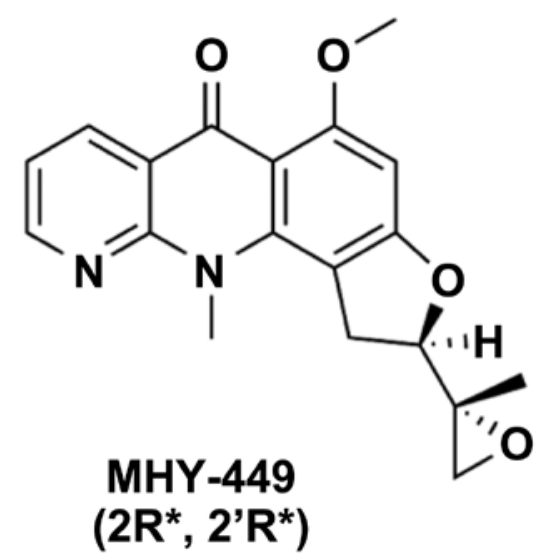

Figure 1. The chemical structure of MHY-449 [( \pm$)-\left(\mathrm{R}^{*}\right)-5$-methoxy-11methyl-2-(( $\left.\mathrm{R}^{*}\right)$-2-methyloxiran-2-yl)-1,2-dihydrobenzofuro[4,5-b][1,8] naphthyridin-6(11H)-one].

separated using a $1.6 \%$ agarose gel, stained with $0.1 \mu \mathrm{g} / \mathrm{ml}$ ethidium bromide, and visualized using an ultraviolet source.

Flow cytometric analysis. The cells were cultured under the appropriate conditions for $24 \mathrm{~h}$, subsequently trypsinized, washed once with cold PBS, and then fixed in $70 \%$ ethanol at $-20^{\circ} \mathrm{C}$ overnight. The fixed cells were stained with cold PI solution $\left(50 \mu \mathrm{g} / \mathrm{ml}\right.$ in PBS) at $37^{\circ} \mathrm{C}$ for $30 \mathrm{~min}$ in the dark. Flow cytometric analysis was performed using a Cytomic FC500 (Beckman Coulter, Istanbul, Turkey). Sub-G1 populations were analyzed using WinCycle software (Phoenix Flow Systems, San Diego, CA, USA).

Protein preparation and western blot analysis. Total cells were lysed in lysis buffer containing $25 \mathrm{mM}$ Tris ( $\mathrm{pH} 7.5)$, $250 \mathrm{mM} \mathrm{NaCl}, 5 \mathrm{mM}$ EDTA, $1 \%$ nonidet P-40, $100 \mu \mathrm{g} / \mathrm{ml}$ phenylmethylsulfonyl fluoride, and protease inhibitor cocktail (Sigma-Aldrich Co. LLC). The lysates were subjected to sodium dodecyl sulfate-polyacrylamide gel electrophoresis (SDS-PAGE) and transferred to polyvinylidene fluoride (PVDF) membranes. The membranes were probed with the relevant primary antibodies overnight, and incubated with horseradish peroxidase (HRP)-conjugated secondary antibodies (Santa Cruz Biotechnology, Inc.), and then visualized using the enhanced chemiluminescence (ECL) detection system (GE Healthcare, Piscataway, NJ, USA).

Caspase activity. The cells were collected and washed with cold PBS. Total cells were incubated with the lysis buffer $(R \& D$ Systems, Inc., Minneapolis, MN, USA) on ice for $10 \mathrm{~min}$. The lyzed cells were centrifuged at $10,000 \mathrm{x} \mathrm{g}$ for $1 \mathrm{~min}$, and $100 \mu \mathrm{g}$ of protein was incubated with $2 \mathrm{X}$ reaction buffer and substrates of the colorimetric tetrapeptides Z-DEVD, Z-IETD, and Ac-LEHD for caspase-3, -8, and -9. The reaction mixtures were incubated at $37^{\circ} \mathrm{C}$ for $2 \mathrm{~h}$, and the enzyme-catalyzed release of p-nitroaniline (pNA) was quantified at $405 \mathrm{~nm}$ using a multi-well reader (Thermo Fisher Scientific).

Measurement of intracellular reactive oxygen species (ROS). The intracellular formation of reactive oxygen species (ROS) 
was determined using 2',7'-dichlorofluorescein diacetate (DCF-DA; Molecular Probes, Eugene, OR, USA). The cells were cultured under the appropriate conditions for $8 \mathrm{~h}$, subsequently trypsinized, and washed twice with cold PBS. The cells were stained with $10 \mu \mathrm{M}$ DCF-DA at $37^{\circ} \mathrm{C}$ for $30 \mathrm{~min}$ in the dark. Fluorescence intensity was quantified using a Cytomic FC 500 (Beckman Coulter).

Statistical analysis. Data were presented as the mean \pm standard deviation (SD) of three separate experiments and analyzed by the Student's t-test. Means were considered significantly different at ${ }^{*} \mathrm{p}<0.05$ or ${ }^{* *} \mathrm{p}<0.01$.

\section{Results}

MHY-449 inhibits AGS cell growth. The inhibitory effect of MHY-449 against AGS cell growth was first evaluated using the MTT assay. As shown in Fig. 2, treatment of AGS cells with $0.125,0.25,0.5$ and $1.0 \mu \mathrm{M}$ MHY-449 for $24 \mathrm{~h}$, significantly reduced the cell viability at the two higher concentrations. The half-maximal inhibitory concentration $\left(\mathrm{IC}_{50}\right)$ of MHY-449 was $\sim 0.4 \mu \mathrm{M}$ at $24 \mathrm{~h}$.

MHY-449 induces apoptosis in AGS cells. We investigated whether the MHY-449-induced inhibition of AGS cell growth was apoptosis-mediated. This was achieved by analyzing the characteristics of cell death, including nuclear morphological changes, by using flow cytometry and a DNA fragmentation assay. The AGS cells treated with MHY-449 showed characteristic features of cell shrinkage and rounding, as well as the formation of apoptotic bodies compared with the untreated

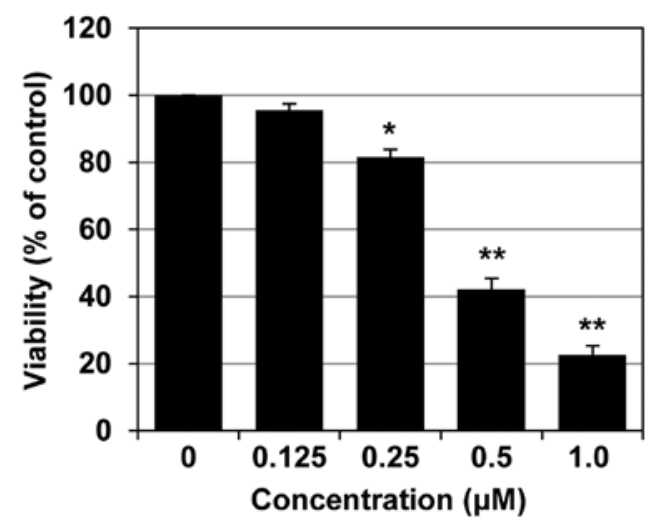

Figure 2. Effect of MHY-449 on the viability of AGS cells. Graph showing viability of cells treated for $24 \mathrm{~h}$ with increasing concentrations of MHY-449. Results are mean $\pm \mathrm{SD}, \mathrm{n}=3$, expressed as a percentage of vehicle-treated control. ${ }^{*} \mathrm{P}<0.05$ and ${ }^{* *} \mathrm{p}<0.01$ compared with vehicle-treated control.

control (Fig. 3A, upper panel). In addition, a significant concentration-dependent reduction in cell count was observed in MHY-449-treated cells.

Consistent with the results of the phase contrast microscopy, Hoechst 33342 staining, confirmed the induction of apoptosis in the AGS cells treated with MHY-449 for $24 \mathrm{~h}$ (Fig. 3A, lower panel). Control cells exhibited normal, round nuclear morphology, while the MHY-449-treated cells exhibited chromatin condensation and fragmentation of nuclei, which are characteristics of apoptosis (Fig. 3A, lower panel).

To confirm the MHY-449-induced cell death to be apoptotic, we performed flow cytometric analysis using Annexin
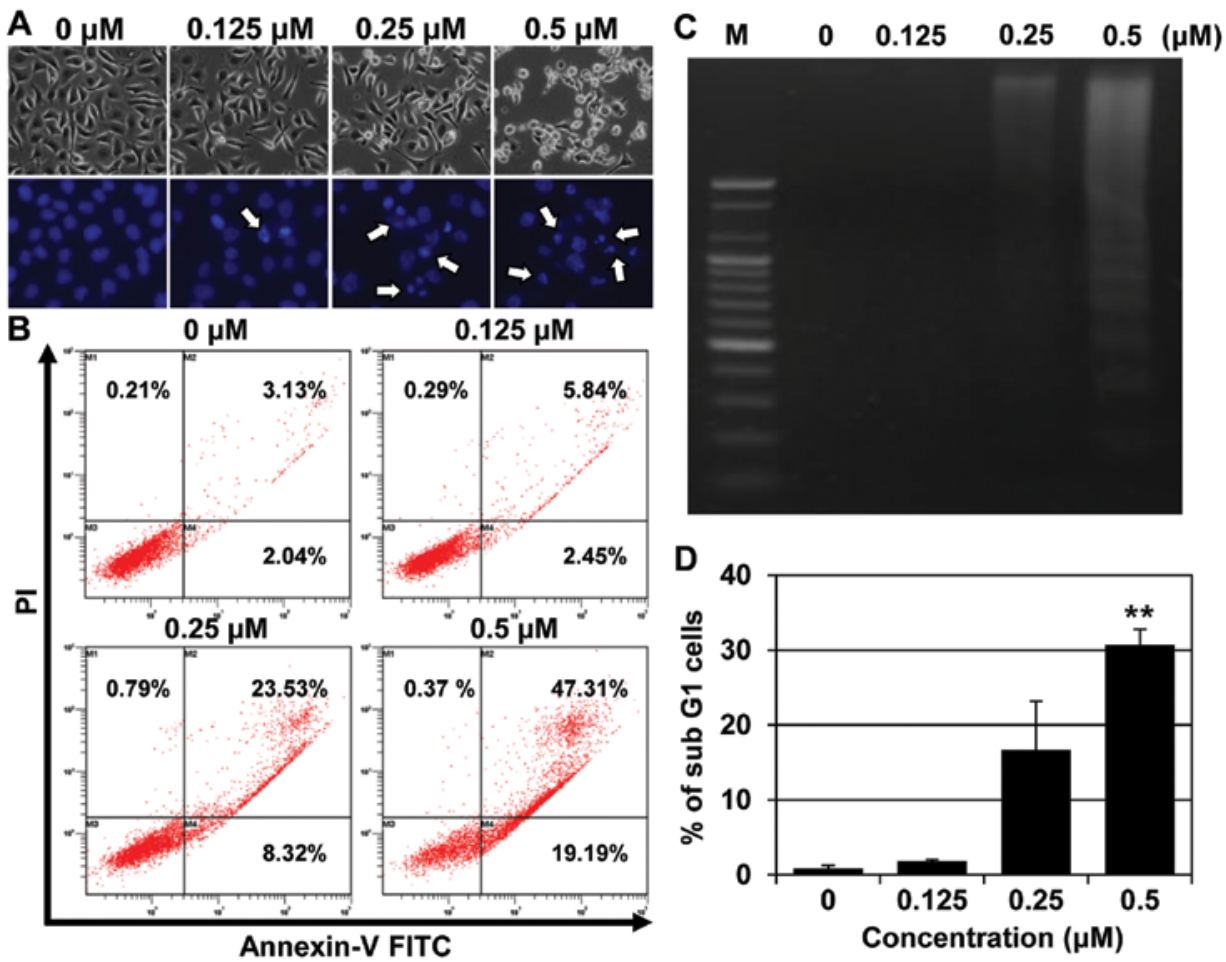

Figure 3. MHY-449-induced apoptosis in AGS cells. (A) Morphological changes in MHY-449-treated cells. Nuclei of AGS cells stained with fluorescent DNAbinding dye (Hoechst 33342). Arrows indicate apoptotic cells. (B) Annexin V-FITC binding and PI uptake in non-permeabilized cells. (C) Representative result of DNA analysis from three independent experiments. M, marker. (D) Presence of cells with sub-G1 DNA content following treatment with MHY-449, to quantify the onset of apoptosis. ${ }^{* *} \mathrm{P}<0.01$ compared with the vehicle-treated control. FITC, fluorescein isothiocyanate; PI, propidium iodide. 
$\mathrm{V}$ and PI staining. As shown in Fig. 3B, the proportion of late apoptotic cells (upper right quadrant, Annexin V/PI-positive) increased from 3.13 to $47.31 \%$ following $24 \mathrm{~h}$ exposure to $0.5 \mu \mathrm{M}$ MHY-449. The results of the flow cytometry also indicated that the MHY-449-triggered apoptosis was concentration-dependent. Another biochemical method commonly used to detect apoptosis is the fragmentation of genomic DNA into multiples of 180 base pairs (bp), which produces a laddering pattern with agarose gel electrophoresis. Treatment of AGS cells with increasing concentrations of MHY-449 for $24 \mathrm{~h}$ resulted in a concentration-dependent internucleosomal DNA fragmentation (Fig. 3C). The effect of MHY-449 on AGS cells was also examined using cell cycle analysis. The cells treated with MHY-449 for $24 \mathrm{~h}$ showed a concentrationdependent increase in the sub-G1 population (Fig. 3D). These findings suggested that MHY-449 triggers the apoptosis of AGS cells.

MHY-449 triggers the apoptosis of AGS cells via extrinsic and intrinsic pathways. We analyzed the modulation of apoptotic markers in MHY-449-induced apoptotic AGS cells, to investigate the mechanisms involved. Based on results from Fig. 2, concentration ranges of $0-0.5 \mu \mathrm{M}$ of MHY-449 were used to examine its effect on apoptosis-related protein expression. As shown in Fig. 4A, MHY-449 decreased the expression of pro-caspase-3, -8 , and -9 in a concentration-dependent manner. Furthermore, MHY-449-treated AGS cells showed proteolytic degradation of PARP, a molecular marker of apoptosis (Fig. 4A).

MHY-449 treatment decreased pro-caspase-8, and therefore, we postulated that its proapoptotic effect may partially be mediated via the extrinsic pathway. We found that MHY-449 treatment upregulated Fas, a death receptor, and its ligand FasL in a concentration-dependent manner (Fig. 4B). We also investigated whether the intrinsic pathway contributed to MHY-449-induced apoptosis. The results showed that levels of the intrinsic apoptotic Bax and the anti-apoptotic Bcl-2 proteins were upregulated and downregulated, respectively, in AGS cells (Fig. 4C). Taken together, these observations suggested that MHY-449 induces intrinsic and extrinsic apoptotic pathways in AGS cells.

MHY-449 upregulates the expression of tumor-suppressor proteins in AGS cells. To explore the anticancer mechanisms of MHY-449, we examined its effects on tumor-suppressor genes. MHY-449 increased the expression of p53 and one of its downstream target genes $\mathrm{p} 21^{\text {WAFI/CIPI }}$ in a concentration-dependent manner (Fig. 4D). We investigated whether MHY-449 also modulates $\mathrm{p} 27^{K I P I}$, which is reportedly involved in the regulation of cancer cell apoptosis (6). As shown in Fig. 4D, MHY-449 induced the expression of p27 in a concentration-dependent manner.

MHY-449 promotes apoptosis via the activation of caspases. Pro-caspases are the precursors of caspases, which are executors of the apoptotic process (7). However, a decrease in pro-caspase levels may not accurately reflect the activation of caspases. Therefore, we evaluated the effects of MHY-449 on caspase activation by using specific substrates. AGS cells treated with MHY-449 showed a concentration-dependent

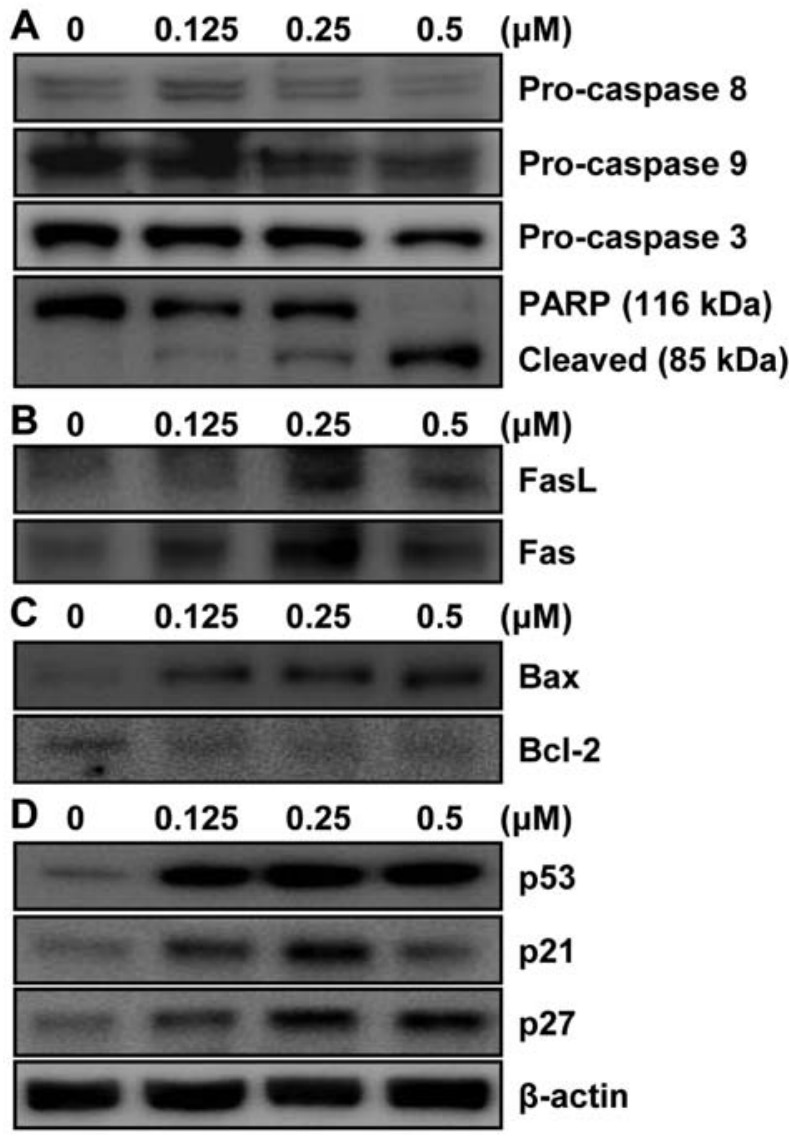

Figure 4. Effects of MHY-449 on apoptotic protein expression in AGS cells Western blot analysis of total lysates of cells treated with increasing concentrations of MHY-449. The membranes were probed with (A) FasL, Fas; (B) pro-caspase-8, -9, -3, PARP (116 kDa); (C) Bax, Bcl-2; (D) p53, p21 ${ }^{\text {WAFI/CIPI }}$, and $\mathrm{p} 27^{K I P I}$. Results represent three independent experiments. Actin was used as a loading control. PARP, poly(ADP-ribose) polymerases; Bcl-2, B-cell lymphoma 2; Bax Bcl-2 associated X protein.

increase in the activities of caspases (Fig. 5A). In addition, the results clearly indicated an almost 3 -fold increase in caspase-3 activation, following $24 \mathrm{~h}$ treatment with MHY-449. This process was activated by upstream signaling molecules such as caspase- 8 and -9 .

To confirm the involvement of caspase activation in MHY-449-induced apoptosis, AGS cells were cultured in the presence and absence of the broad-spectrum caspase inhibitor Z-VAD-FMK and analyzed using Annexin V-FITC/PI double staining. As shown in Fig. 5B, the pretreatment of cells with Z-VAD-FMK inhibited the MHY-449-induced apoptosis albeit not completely. This result was further confirmed by measuring PARP cleavage, which is a substrate of the effector caspase-3, under identical experimental conditions. Consistent with the cell death measured by flow cytometry, western blot analysis of PARP showed that pretreatment with Z-VAD-FMK markedly inhibited MHY-449-induced cleavage of PARP (Fig. 5C). This result strongly suggested that caspase activation plays an important role in caspase-induced apoptosis in AGS cells.

MHY-449 induces apoptosis in AGS cells via ROS generation. The double-edged sword property of ROS reported to play a critical role in determining death or survival cell 

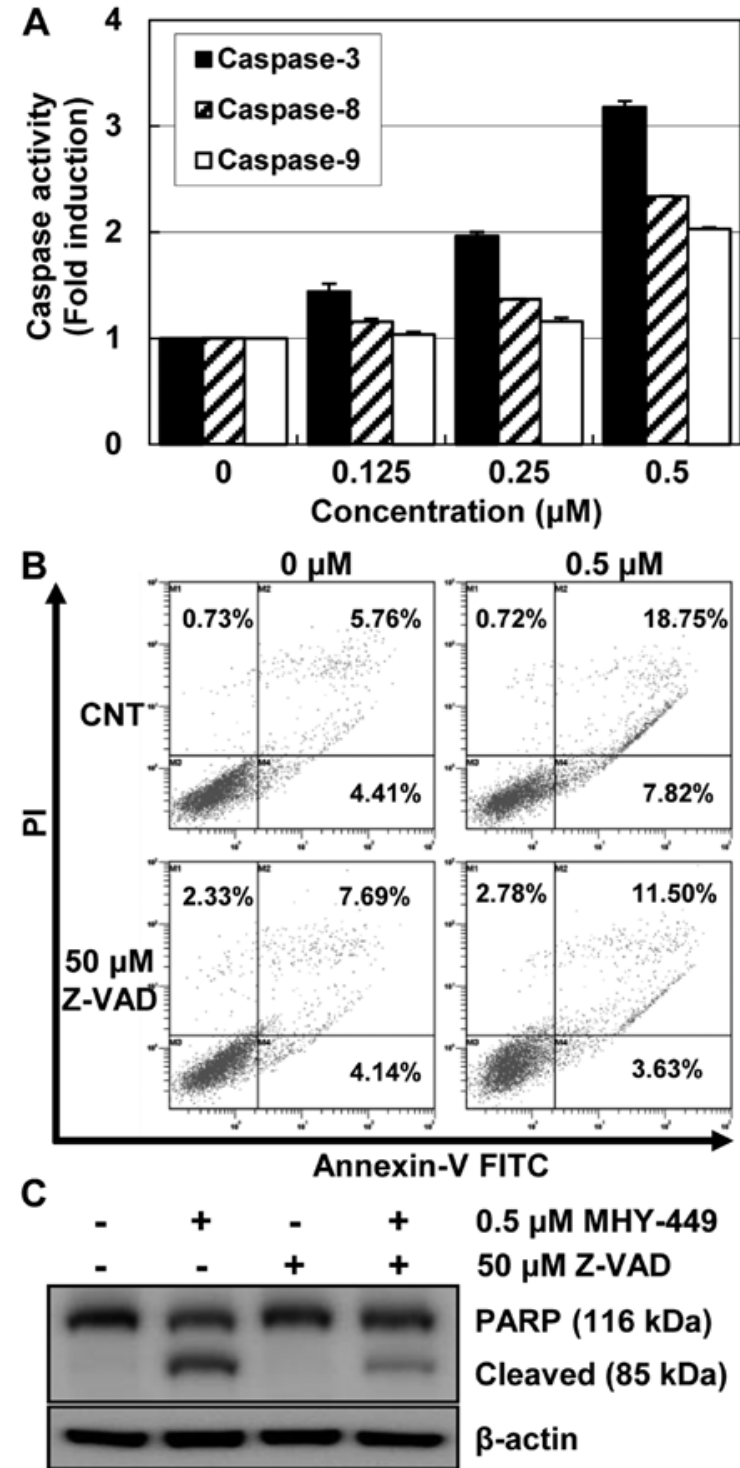

Figure 5. Effect of MHY-449 on caspase activation in AGS cells. (A) MHY449-treated cell lysates assayed for in vitro caspase- $3,-8$, and -9 activity using Z-DEVD-pNA, Z-IETD-pNA, and Ac-LEHD-pNA substrates, respectively. The released fluorescent products were measured. Data are presented as the mean \pm SD of duplicate samples. Results represent one of three independent experiments. (B) Cells stained with Annexin V-FITC/PI. CNT, control. (C) Western blot analysis of PARP in total lysates of cells treated with $50 \mu \mathrm{M}$ Z-VAD-FMK and $0.5 \mu \mathrm{M}$ MHY-449. Results represent three independent experiments. Actin was used as a loading control. FITC, fluorescein isothiocyanate; PI, propidium iodide; PARP, poly(ADP-ribose) polymerases.

fate $(8,9)$. Thus, inducing ROS is considered as a strategy to treat cancer (10). Therefore, we examined the generation of ROS by MHY-449, to determine whether this was the mechanism of apoptosis induction. The intracellular ROS level was quantified using DCF-DA, a fluorescent probe. We found that MHY-449 induced ROS, and the maximum intracellular level was observed $8 \mathrm{~h}$ after exposure to $0.5 \mu \mathrm{M}$ (Fig. 6A). To identify the cause-effect relationship between ROS generation and apoptosis, we examined the effects of NAC, a widely used thiol-containing ROS scavenger, on MHY-449-treated cells. As shown in Fig. 6B, the pretreatment of cells with NAC significantly abrogated cell death in MHY-449-treated cells $(\mathrm{p}<0.05)$, but affected cell viability minimally in untreated
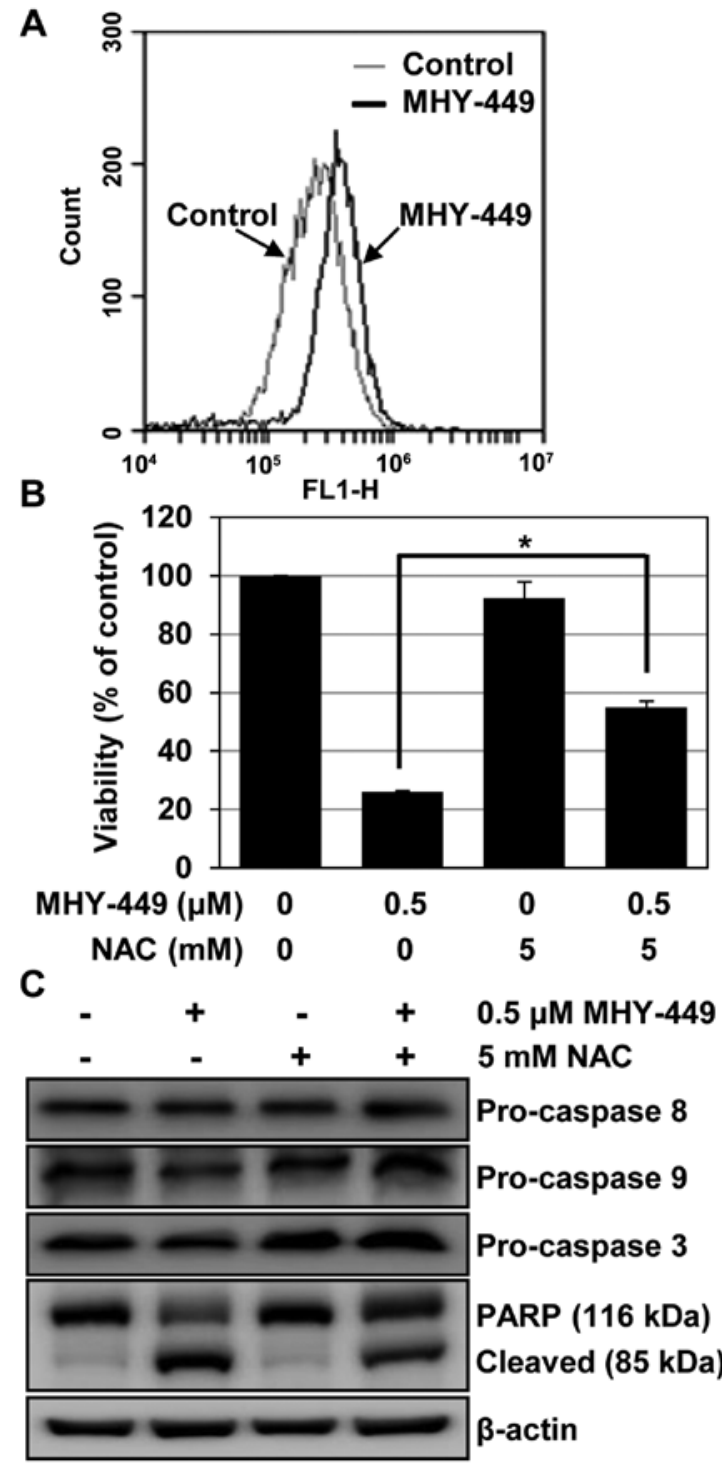

Figure 6. Role of reactive oxygen species (ROS) generation in MHY-449induced apoptosis in AGS cells. (A) The cells were treated with $0.5 \mu \mathrm{M}$ MHY-449 for $8 \mathrm{~h}$ and stained with DCF-DA. Data are representative of three independent experiments with similar results. (B) Viability of cells treated with or without $0.5 \mu \mathrm{M}$ MHY-449 after pretreatment with or without $5 \mathrm{mM}$ NAC. Data are presented as the mean \pm SD of three independent experiments. ${ }^{*} \mathrm{P}<0.05$ compared with MHY-449-treated cells. (C) Western blot analysis of total lysates of cells treated with or without $0.5 \mu \mathrm{M}$ MHY-449 after pretreatment with or without $5 \mathrm{mM} \mathrm{NAC}$, for pro-caspase $8,-9$ and -3 , and PARP. Results represent three independent experiments. Actin was used as a loading control. DCF-DA, dichlorofluorescin diacetate; NAC, N-acetylL-cysteine; PARP, poly(ADP-ribose) polymerases.

cells. In agreement with these observations, we found that sequestration of ROS by NAC effectively suppressed the decline in pro-caspase levels and prevented MHY-449induced PARP cleavage in AGS cells (Fig. 6C). Collectively, these results suggested that an increase in ROS generation is required for MHY-449-induced apoptosis in AGS cells.

\section{Discussion}

A previous study indicated that MHY-449 exhibits anticancer properties in human prostate and breast cancer cells (3). These anticancer effects were mediated by cytotoxicity and induction 
of cell cycle arrest (3). Our previous studies have also shown that MHY-449 induced the apoptosis of colon and prostate cancer cells by caspase-mediated or extracellular signalregulated kinases (ERK)-dependent signaling pathways or both $(4,5)$. However, the anticancer potential of MHY-449 in other types of cancer and its detailed mechanism of action has not been fully elucidated. As mentioned previously, MHY-449 is a novel molecule, based on psorospermin with a xanthone template and acronycine derivatives (3).

The molecular mechanism of action of the benzoacronycine derivative S23906-1 is the most characterized of several synthetic derivatives. S23906-1 is reported to alkylate guanines in the minor groove of the DNA helix and subsequently destabilize base pairing $(11,12)$. This destabilization causes helix opening, which appears to be associated with its cytotoxic activity $(11,12)$. In addition, despite its promising in vivo activity, the mechanism of the anticancer cell cytotoxicity of this acronycine derivative largely remains unknown (13). It was shown recently that $\mathrm{S} 23906-1$ induces cyclin E, inhibits DNA synthesis (14), alters mitochondrial functions, stimulates ROS production, and activates caspases (15). The structural similarity between MHY-449 and S23906-1 led to the hypothesis that their underlying anticancer mechanisms may also be similar and mediated via DNA-intercalation and alkylation, cell cycle perturbation or apoptosis. Of note, our recent findings showed the anticancer activity of MHY-449 (4). In addition, we showed that MHY-449-induced apoptosis was mediated through downregulation of the Akt/Forkhead-Box Class $\mathrm{O}$ (FoxO) 1 and activation of ERK (4). Those results provided a possibility that the anticancer property of MHY-449 is not dependent on DNA alkylating or stability. Therefore, it is postulated that other mechanisms may mediate the apoptotic effect.

The present study provides insight into the mode of action of MHY-449 and finds several important points: i) MHY-449 significantly inhibits GC cell growth; ii) MHY-449 induces apoptosis; iii) caspase activation appears to be one of the major mechanisms of MHY-449-triggered apoptosis; iv) MHY-449 modulates the expression of genes involved in the extrinsic and intrinsic apoptotic pathways; and v) MHY-449-induced apoptosis is ROS-dependent, as shown by the ability of MHY-449 to generate ROS, and that NAC-mediated quenching of ROS abrogated the MHY-449-induced apoptosis.

We found that MHY-449 inhibited GC cell growth in a concentration-dependent manner. This result is in agreement with those of recent studies showing that MHY-449 suppresses cell proliferation in breast $(3)$, prostate $(3,4)$ and colonic cancer cells (5). The mechanism by which MHY-449 inhibits cell growth is not completely understood. However, it has been shown that MHY-449 upregulates Fas/FasL or Bax or both, and downregulates Bcl-2 expression, which leads to apoptosis $(4,5)$. Apoptosis can be induced via activation of the intrinsic or extrinsic pathways. The intrinsic pathway involves mitochondrial disruption by pro-apoptotic Bcl-2 family members and by Bax oligomerization, which consequently releases cytochrome $c$ (16). We found that the expression of Bcl-2 decreased whereas that of Bax increased in MHY-449treated AGS cells. In addition, we observed that MHY-449 induces the expression of Fas and FasL, which are the major mediators of extrinsic apoptosis signaling (17). Therefore,
MHY-449 activated major extrinsic and intrinsic pathways, leading to apoptosis.

The tumor-suppressor p53 is known to induce cell cycle arrest, apoptosis, or senescence as a protective measure against cancer (18). As a transcription factor, p53 regulates multiple target genes, such as p21 WAFI/CIPI , a cyclin-dependent kinase (CDK) inhibitor (18). This inhibitor binds and inhibits the cyclin/CDK complexes, thereby effectively blocking cell cycle progression (18). In addition to its CDK inhibitory function, p2 $1^{\text {WAFI/CIPI }}$ also negatively or positively modulates the apoptosis-inducing function of p53 (19). In our study, MHY-449 increased the expression of p53 and p $21^{\text {WAFI/CIPI }}$ in GC cells in a concentration-dependent manner, suggesting that MHY-449 has potential cytotoxicity against GC. Previous studies reported that the upregulation of $\mathrm{p} 27^{K I P I}$, an endogenous CDK inhibitor, inhibits the growth of various cancer cell models $(6,20)$. We also found that MHY-449 induced p27 ${ }^{K I P I}$ protein levels. In agreement with this finding, our previous study showed that MHY-449 caused G2/M phase arrest in HCT116 colon cancer cells, which was associated with the upregulation of $\mathrm{p} 21^{\text {WAFI/CIPI }}$ and $\mathrm{p} 27^{K I P I}$ (5). The effect of MHY-449 on cell cycle progression in AGS cells remains to be explored. However, a possible explanation is that the inhibition of cell growth by MHY-449 may be attributable to the induction of $\mathrm{p} 21^{\text {WAFI/CIPI }}$, $27^{\text {KIPI }}$, or p53 or their combination, in response to MHY-449.

We also found that MHY-449 activates caspases, which is a pivotal process in apoptosis. This corroborates our previous studies that MHY-449 activates caspase-3, -8 and -9 , which leads to cleavage of PARP in HCT116 colon and PC-3 prostate cancer cells $(4,5)$. Apoptosis can occur through caspasedependent and -independent mechanisms $(21,22)$. Therefore, we used a pan-caspase inhibitor Z-VAD-FMK to define the role of caspase activation in MHY-449-induced cell death. Of note, $50 \mu \mathrm{M}$ Z-VAD-FMK effectively prevented but did not completely rescue cells from MHY-449-induced apoptosis. These results suggest the possibility that mechanisms other than apoptosis may be responsible for the MHY-449-induced cell death. However, the flow cytometry data showed clearly that the MHY-449-mediated caspase-independent cell death was not caused by necrosis. More studies are required to determine the molecules involved and their underlying mechanisms of mediating MHY-449-induced caspase-independent cell death. Therefore, it would also be worth to investigate the ability of MHY-449 to induce cell death via pathways other than apoptosis such as autophagy. These potential alternative pathways may contribute to caspase-independent cell death.

To the best of our knowledge, the present study is the first to investigate the ROS-mediated anticancer effects of the novel dihydrobenzofuro[4,5-b][1,8]naphthyridin-6-one derivative. Several anticancer agents such as cisplatin, doxorubicin, mitomycin $\mathrm{C}$, and etoposide reportedly exert their effects at least in part, via induction of ROS (23). ROS, which were predominantly produced in the mitochondria, may play a role as active mediators in the regulation of programmed cell death when produced in excess. ROS achieve this by inducing mitochondrial membrane depolarization and release of mitochondrial factors, which activate caspases and cause nuclear condensation (24). Pretreatment with the antioxidant NAC significantly abrogated the MHY-449-induced decrease in pro-caspase levels as well as subsequent cell death, thereby, 
suggesting that ROS was involved in the upstream events of caspase activation by MHY-449 in AGS cells. ROS also modulate apoptosis by controlling apoptosis-related proteins. For instance, ROS exert a direct role in the induction of Fas or FasL or both $(20,21)$. They also regulate the expression of Bcl-2 proteins and eventually trigger apoptosis $(22,23)$. Although the effect of NAC on the modulation of those proapoptotic or anti-apoptotic proteins by MHY-449 have yet to be investigated, it is very likely that the apoptogenic effect of MHY-449 occurs through generation of ROS and the ROS-associated apoptotic pathway.

In conclusion, MHY-449 is a potent inducer of apoptosis in AGS cells. MHY-449 causes apoptosis in AGS cells primarily through ROS generation and partly through activation of the caspase cascade. Based on these results, further preclinical studies using appropriate animal models are required to explore the potential of MHY-449 as an anticancer agent.

\section{Acknowledgements}

The present study was supported by the National Research Foundation of Korea (NRF) grant, funded by the Korea Government (MSIP, no. 2009-0083538). We would like to thank the Aging Tissue Bank for providing research information.

\section{References}

1. Orditura M, Galizia G, Sforza V, Gambardella V, Fabozzi A, Laterza MM, Andreozzi F, Ventriglia J, Savastano B, Mabilia A, et al: Treatment of gastric cancer. World J Gastroenterol 20: 1635-1649, 2014.

2. Sun J, Song Y, Wang Z, Chen X, Gao P, Xu Y, Zhou B and Xu H: Clinical significance of palliative gastrectomy on the survival of patients with incurable advanced gastric cancer: A systematic review and meta-analysis. BMC Cancer 13: 577, 2013.

3. Kang JA, Yang Z, Lee JY, De U, Kim TH, Park JY, Lee HJ, Park YJ, Chun P, Kim HS, et al: Design, synthesis and anticancer activity of novel dihydrobenzofuro $[4,5-b][1,8]$ naphthyridin6-one derivatives. Bioorg Med Chem Lett 21: 5730-5734, 2011.

4. Lee SH, Kang YJ, Sung B, Kim DH, Lim HS, Kim HR, Kim SJ, Yoon JH, Moon HR, Chung HY, et al: MHY-449, a novel dihydrobenzofuro[4,5-b][1,8] naphthyridin-6-one derivative, induces apoptotic cell death through modulation of $\mathrm{Akt} / \mathrm{FoxO} 1$ and ERK signaling in PC3 human prostate cancer cells. Int J Oncol 44: 905-911, 2014.

5. Hwang HJ, Kang YJ, Hossain MA, Kim DH, Jang JY, Lee SH, Yoon JH, Moon HR, Kim HS, Chung HY, et al: Novel dihydrobenzofuro[4,5-b][1,8]naphthyridin-6-one derivative, MHY-449, induces apoptosis and cell cycle arrest in HCT116 human colon cancer cells. Int J Oncol 41: 2057-2064, 2012.

6. Hiromura K, Pippin JW, Fero ML, Roberts JM and Shankland SJ: Modulation of apoptosis by the cyclin-dependent kinase inhibitor p27(Kip1). J Clin Invest 103: 597-604, 1999.
7. Kaufmann SH, Lee SH, Meng XW, Loegering DA, Kottke TJ, Henzing AJ, Ruchaud S, Samejima K and Earnshaw WC: Apoptosis-associated caspase activation assays. Methods 44: 262-272, 2008

8. Wang J and Yi J: Cancer cell killing via ROS: To increase or decrease, that is the question. Cancer Biol Ther 7: 1875-1884, 2008.

9. Wu WS: The signaling mechanism of ROS in tumor progression. Cancer Metastasis Rev 25: 695-705, 2006.

10. Watson J: Oxidants, antioxidants and the current incurability of metastatic cancers. Open Biol 3: 120144, 2013.

11. David-Cordonnier MH, Laine W, Lansiaux A, Kouach M, Briand G, Pierré A, Hickman JA and Bailly C: Alkylation of guanine in DNA by S23906-1, a novel potent antitumor compound derived from the plant alkaloid acronycine. Biochemistry 41 : 9911-9920, 2002

12. Thi Mai HD, Gaslonde T, Michel S, Tillequin F, Koch M, Bongui JB, Elomri A, Seguin E, Pfeiffer B, Renard P, et al: Structure-activity relationships and mechanism of action of antitumor benzo[b]pyrano[3,2-h] acridin-7-one acronycine analogues. J Med Chem 46: 3072-3082, 2003.

13. Guilbaud N, Kraus-Berthier L, Meyer-Losic F, Malivet V, Chacun C, Jan M, Tillequin F, Michel S, Koch M, Pfeiffer B, et al: Marked antitumor activity of a new potent acronycine derivative in orthotopic models of human solid tumors. Clin Cancer Res 7: 2573-2580, 2001.

14. Léonce S, Pérez V, Lambel S, Peyroulan D, Tillequin F, Michel S, Koch M, Pfeiffer B, Atassi G, Hickman JA, et al: Induction of cyclin $\mathrm{E}$ and inhibition of DNA synthesis by the novel acronycine derivative S23906-1 precede the irreversible arrest of tumor cells in S phase leading to apoptosis. Mol Pharmacol 60: 1383-1391, 2001.

15. Kluza J, Lansiaux A, Wattez N, Hildebrand MP, Léonce S, Pierré A, Hickman JA and Bailly C: Induction of apoptosis in HL-60 leukemia and B16 melanoma cells by the acronycine derivative S23906-1. Biochem Pharmacol 63: 1443-1452, 2002.

16. Suen DF, Norris KL and Youle RJ: Mitochondrial dynamics and apoptosis. Genes Dev 22: 1577-1590, 2008.

17. Waring $\mathrm{P}$ and Mullbacher A: Cell death induced by the Fas/Fas ligand pathway and its role in pathology. Immunol Cell Biol 77: 312-317, 1999.

18. Vogelstein B, Lane D and Levine AJ: Surfing the p53 network. Nature 408: 307-310, 2000.

19. Abbas T and Dutta A: p21 in cancer: Intricate networks and multiple activities. Nat Rev Cancer 9: 400-414, 2009.

20. Craig C, Wersto R, Kim M, Ohri E, Li Z, Katayose D, Lee SJ, Trepel J, Cowan K and Seth P: A recombinant adenovirus expressing p27Kip1 induces cell cycle arrest and loss of cyclin-Cdk activity in human breast cancer cells. Oncogene 14: 2283-2289, 1997.

21. Tait SW and Green DR: Caspase-independent cell death: Leaving the set without the final cut. Oncogene 27: 6452-6461, 2008.

22. Kolenko VM, Uzzo RG, Bukowski R and Finke JH: Caspasedependent and -independent death pathways in cancer therapy. Apoptosis 5: 17-20, 2000.

23. Fang J, Nakamura $\mathrm{H}$ and Iyer AK: Tumor-targeted induction of oxystress for cancer therapy. J Drug Target 15: 475-486, 2007.

24. Zamzami N, Marchetti P, Castedo M, Decaudin D, Macho A, Hirsch T, Susin SA, Petit PX, Mignotte B and Kroemer G: Sequential reduction of mitochondrial transmembrane potential and generation of reactive oxygen species in early programmed cell death. J Exp Med 182: 367-377, 1995. 